\title{
Author Correction: Childhood ecology influences salivary testosterone, pubertal age and stature of Bangladeshi UK migrant men
}

Kesson Magid (D, Robert T. Chatterton, Farid Uddin Ahamed and Gillian R. Bentley

Correction to: Nature Ecology \& Evolution https://doi.org/10.1038/s41559-018-0567-6, published online 25 June 2018.

In the version of this Article originally published, the units for the 'Weight' column in Table 1 were incorrect; they should have been kg. This has now been corrected.

Published online: 23 July 2018

https://doi.org/10.1038/s41559-018-0620-5 